\title{
The Effects of Conditionality Monitoring on Educational Outcomes: Evidence from Brazil's Bolsa Família Programme
}

\author{
Luis Henrique Paiva ${ }^{1}$ \\ https://orcid.org/0000-0001-9197-7332 \\ Fábio Veras Soares ${ }^{2}$ \\ https://orcid.org/0000-0002-7192-250X \\ Iara Azevedo Vitelli Viana ${ }^{3}$ \\ https://orcid.org/0000-0002-0991-1762 \\ Flavio Cireno 4 \\ https://orcid.org/0000-0003-3830-9567 \\ Ana Clara Duran 5 ,* \\ https://orcid.org/0000-0001-7317-5790
}

${ }^{1}$ Instituto de Pesquisa Econômica Aplicada, Brasília/DF, Brazil

2International Policy Centre for Inclusive Growth, Brasília/DF, Brazil

${ }^{3}$ Universidade Federal de Minas Gerais, Belo Horizonte/MG, Brazil

${ }^{4}$ Fundação Joaquim Nabuco, Recife/PE, Brazil

5Universidade Estadual de Campinas, Campinas/SP, Brazil

Conditional cash transfer programmes have been adopted by several developing countries. Despite their acceptance, the independent role of the conditionalities on education and health remain under scrutiny. We have used an ecological design to study the association between conditionality monitoring and educational outcomes in Brazil's Bolsa Família programme. As programme coverage (taken as a proxy of cash transfers) and monitoring and enforcement of the educational conditionalities (proxy of conditionalities) are not correlated at the municipal level, this study fits a number of different ordinary least square (OLS) and growth-curve models to explain variation in dropout rates and school progression in basic education in public schools across municipalities. After controlling for a number of covariates, we did not find a significant association between Bolsa Família coverage and dropout and progression rates. On the other hand, monitoring of school attendance was negatively associated with dropout rates and positively associated with school progression (in the OLS models and in the initial status of the growth-curve models). The association between attendance monitoring and the rate of change of educational indicators in growth curve models was not the same, however, suggesting that its possible positive effect on educational indicators are not strong enough to affect a general tendency for these indicators to converge in the recent Brazilian context.

Keywords: Bolsa Família; cash transfer; conditionality; education; monitoring and evaluation.

http://doi.org/10.1590/1981-3821202100010001

For data replication, see:

Correspondence: Luis Henrique Paiva. E-mail: luis.paiva@ipea.gov.br

This publication is registered under a CC-BY Licence.

*Funding: United Kingdom Department for International Development. 
Conditional cash transfers (also referred to as human development income transfer) programmes, usually referred to as conditional cash transfers (CCT), emerged in Latin America in the 1990s and since then have been implemented (and adapted) by many developing countries (BARRIENTOS, 2013). Worldwide, the number of CCT programmes increased from twenty-seven in 2008 to sixty-seven in 2017 (WORLD BANK, 2017). Latin America hosts the majority of these programmes. CCT beneficiary families need to comply with certain conditions, mostly related to the health, nutrition, and education of their children, to receive the regular payments offered by the programmes. Over the past twenty years, these programmes have become an important component of the social protection systems of their respective countries (LORENZO, 2013).

Among the key features of CCT programmes, two are particularly controversial, namely their targeted nature and the adoption of conditionalities. Despite the ongoing debate about the pros and cons of a targeted versus a universalistic approach to cash transfers and criticisms related to the potential exclusionary effect of targeting, it would appear that targeted cash transfer programmes have become popular among the policymakers of middle-income countries. Similarly, the adoption of conditionalities by cash transfer programmes has also been criticised. However, in this case, even pragmatic policymakers seem to be unsure about the need to impose conditionalities and increase programme costs, particularly when the most important objective of the programme is to reduce poverty rather than to induce any kind of behavioural change (PELLERANO and BARCA, 2014).

Monitoring conditionality compliance is not simple and costless. It requires strong coordination between the CCT implementing agency and those institutions in charge of the supply of education and health care services. It is not by chance that many CCTs are in fact unconditional, despite having conditionalities mentioned in their official documents and/or legal frameworks ${ }^{2}$. In this context, policymakers and practitioners are often interested in obtaining more evidence about the

\footnotetext{
2See, for instance, Ecuador's Bono de Desarrollo Humano, available at <http://www.inclusion.gob.ec/programas-y-servicios/servicio-de-proteccion-social/bono-dedesarrollo-humano/ $>$, and South Africa's Child Support Grant, available at <http://www.gov.za/services/child-care-social-benefits/child-support-grant>.
} 
effectiveness of conditionalities. This explains to some extent why the debate on whether to adopt conditionalities for cash transfers programmes "has been at the forefront of recent global policy discussions" (BAIRD et al., 2013, p. 14).

The aim of this paper is to assess whether the coverage and the monitoring of the education-related conditionality that is part of the Brazilian CCT programme Bolsa Família is associated with any positive changes on educational outcomes.

The paper is structured as follows: section two presents a review of the key arguments in favour of and against conditionalities. Section three reviews the evidence produced so far about the additional effect of conditionalities in the context of CCTs worldwide, as well as the methodologies used to estimate this additional effect. Section four puts forward a statistical model based on 'growth model' literature to estimate the effect of programme coverage and of conditionality monitoring at the municipal level on certain key educational indicators, namely drop-out and progression rates. Finally, section five discusses the main results of the estimates, and section six summarises the main conclusions.

\section{Conditionalities: pros and cons}

Human development CCTs are meant to tackle poverty both in the short- and medium/long-term. The cash transfer component is intended to reduce poverty in the short term, whereas the increase in the demand for education and health care services (induced by conditionalities) is intended to reduce poverty in the medium/long-term. Under this framework, conditionalities are useful to reinforce behaviour that affects "enduring aspects of intergenerational poverty transmission" (PELLERANO and BARCA, 2014, p. 02). This theory of change assumes that the target population of CCT programmes are faced with a poverty trap largely due to the low accumulation of human capital, which could be avoided through investments in the health and education of future generations. CCTs have the potential to incentivise such investments through conditionalities and thus break 
the intergenerational cycle of poverty. This paper seeks to evaluate this theory of change ${ }^{3}$.

Arguments in favour of conditionalities can be grouped into three sets. The first set of arguments states that the existence of market failures prevents poor families from achieving an optimal level of private investments in education and health. Lack of information about the rate of return of education, differences in intertemporal discount rates (with parents being more 'impatient' and disregarding future consumption at a higher rate than their children), or intra-household bargaining issues (with mothers having less say on the choice of the desirable level of schooling of their children and/or girls being discriminated against) can result in a sub-optimal level of investment in human capital for future generations (BAIRD et al., 2013, pp. 10-11).

The second set of arguments highlights that, even when investments in education and health services are privately optimal, they may be sub-optimal from a social point of view. One example is the potential positive externalities of higher levels of education and health status on economic productivity. These positive externalities are not taken into account by households when making decisions about their private investments in education and/or health (BAIRD et al., 2013, p. 11).

The third set of arguments focuses on the political sustainability of cash transfers, which would be more palatable to taxpayers if transfers were not perceived as simple handouts but, rather, as payments in exchange for socially desirable behaviour, such as beneficiaries sending their children to school. Under this framework, conditionalities are seen as "a useful means to buy the support of the middle classes" for the programme and to improve the political feasibility of cash transfers to people living in poverty, according to Pellerano and Barca (2014, p. 13). There seems to be evidence that conditionalities can be helpful to increase the support of cash transfer among the better-off (ZUCCO, LUNA and BAYKAL, 2020).

\footnotetext{
${ }^{3}$ The authors are aware that the discussion of the educational indicators considered here (dropout and progression rates) extends far beyond their relationship with conditional cash transfers. The objective of the paper, however, is not to present a comprehensive explanation for the evolution of these indicators over the recent past in Brazil, but rather to test the theory of change embodied by CCTs.
} 
The fourth and final set of arguments (from a perspective of rights, which is very present in the Brazilian debate) posits that conditionalities should be understood as a type of contract between the state and beneficiaries, whereby commitments are not only pledged by families, but also (and more especially, it might be said) by the state. From this perspective, conditionalities are a tool to increase poor people's access to educational and health services and reduce inequalities (see, for instance, AGATTE, 2010; XIMENES and AGATTE, 2011). The monitoring of conditionalities could also generate an effective signal that something is 'wrong' with beneficiary families (for example, that they are not sending kids to school, attending health clinics regularly, etc) and mobilise public agencies towards them. This approach seems interesting because it shifts the usual outlook on the theme: conditionalities should be adopted to boost not only demand for public services, but especially to boost and adjust their supply. However, this view can be considered relatively rare around the world: it seems to be embedded particularly in the Brazilian context, where a soft approach to conditionalities was adopted by Bolsa Família.

The first and second sets of arguments rely on the idea that while the 'income effect' generated by both CCTs and UCTs represents a relief to some private financial constraints in accessing public services (education and health care), only the conditional aspect of a CCT adds a 'price effect' by reducing the opportunity cost of accessing these services, either helping families to achieve optimal levels of investment in human capital when there are market failures or providing them with incentives (through the conditionalities) to meet a socially optimal level of investment that is higher than the private optimal level. Consequently, an independent effect of conditionalities should be expected on top of the income effect. Occasional effects of conditionalities on public services, not on beneficiary families, should also be noted in addition to effects produced by transfers. However, it can be noted that the argument that conditionalities are important for the political sustainability of CCT programmes does not imply an additional effect on the outcomes of interest.

On the other hand, there are at least seven arguments normally used against the adoption of conditionalities in the context of poverty reduction cash transfers. 
The first argument is anchored on the rights-based approach. According to this approach, access to a minimum level of consumption is seen as a right and, therefore, should not be conditional on any specific actions or behaviours. It is thus unacceptable to deny access to a minimum level of consumption/income (through cash transfers) either through exclusion from the programme in geographical areas that lack a supply of education and/or health services or through individual sanctions for non-compliance with conditionalities (HANLON et al., 2010, p. 125; PELLERANO and BARCA, 2014, p. 07). As this argument is based on principles, once it is accepted that a minimum benefit (or a minimum level of consumption provided by this benefit) is a right, and that rights are unconditional, it is unnecessary to provide any evidence that conditionalities have an additional effect on top of the income effect.

The second argument against conditionalities is that poor people (just like the non-poor) want their children to go to school and receive proper health care. What prevents them from doing so (from the demand side) is a lack of income (BAIRD et al., 2013, p. 10; HANLON et al., 2010, p. 125). Thus, UCTs should be as effective as CCTs in improving health and educational outcomes. In other words, conditional or unconditional transfers reduce the private costs of access education and health services and should equally be associated with better indicators in these areas $^{4}$.

The third argument is based on the idea that it is not necessary to enforce conditions to induce behavioural change. According to this approach, simply adequately labelling some cash transfer programmes can ensure the 'price effect' associated with the conditionalities. The mere statement that a cash transfer programme is a social benefit whose objective is to improve children's health and education functions as a 'nudge' that can potentially change the behaviour of beneficiary families in ways that other, unlabelled, cash transfers cannot. Similarly, the fact that CCTs are, in general, paid preferably to women (mothers) can also change the way in which the benefit is spent, in general favouring more children-

\footnotetext{
${ }^{4}$ This argument assumes that poor people are as well informed as wealthy people about the returns of education and that they discount future consumption at the same discount rate as wealthy people, which is obviously arguable.
} 
related expenses than other sources of income controlled by men (fathers) (PELLERANO and BARCA, 2014, pp. 08-09) 5 .

A fourth argument is that conditions can cause stigma by implying that poor people do not know what is good for them and/or create opportunities for corruption by officials responsible for certifying that conditions are met (DE BRAUW and HODDINOTT, 2008; HANLON et al., 2010).

A fifth argument is that conditionalities can actually worsen the accuracy of the targeting of cash transfer programmes and compromise some of their positive impacts on education and health outcomes (DE BRAUW and HODDINOTT, 2008). Complying with conditionalities imposes private costs on beneficiary families, and, as a corollary, these costs can be relatively larger for the poorest beneficiaries. Consequently, voluntary drop-out, exclusion from the programme or benefit cuts related to non-compliance can disproportionately affect those who are most vulnerable. In this scenario, UCTs can have larger positive impacts than CCTs on some outcomes, as they do not exclude the most vulnerable ${ }^{6}$.

The sixth argument is that demand-side interventions (including CCTs) tend to be ineffective for some educational indicators, such as scores in learning tests, which only improve through supply-side interventions. Reimers et al. (2006) argue that adopting CCTs can drive away resources that would be better employed in educational policies by focusing on the supply side. At the time their paper was published, most of the evidence did not show impacts of CCTs on learning, but since then the evidence is better described as mixed. For instance, while authors such as Akresh et al. (2013) and Baez and Camacho (2011) found no effect of CCT interventions on learning outcomes, Baird et al. (2011) and Simões and Sabates (2014) suggest some positive impacts.

\footnotetext{
${ }^{5}$ Paxson and Schady (2010), in their experimental evaluation of Ecuador's UCT programme Bono de Desarrollo Humano (BDH), found positive effects of cash transfers on the physical, cognitive, and socio-emotional development of beneficiary children that were much larger than what would be expected from a pure 'income effect'.

${ }^{6}$ Paxson and Schady (2010) also found that the positive impacts of Ecuador's BDH were larger for the poorest households benefiting from the programme. Exclusionary factors such as sanctions due to non-compliance with conditionalities can dull programme impacts due to the potential exclusion of the poorest families.
} 
Finally, the seventh argument is related to the concern that conditionality monitoring is costly and that occasional positive effects on educational and health outcomes have to be very significant to make it cost-effective (PELLERANO and BARCA, 2014). Monitoring-related costs are especially relevant in low-income countries (ADATO and HODDINOTT, 2009), where governments and NGOs supply educational and health services in an uncoordinated fashion and there are considerable coverage gaps. However, in middle-income countries - where public services are more widespread and data on attendance to school and health clinics is collected regardless, the costs of coordination and of gathering information may not be too high?.

\section{The evidence so far}

The literature that presents evidence on the additional impact of conditionalities on outcomes of interest for a human development cash transfer programme can be divided into three groups. The first group encompasses quasiexperimental evaluations that use 'glitches' in the implementation of CCT programmes to try to assess whether conditionalities have any additional impacts on cash transfer components. The second group comprises studies whose evaluation designs were based on randomising the conditionality component of the cash transfer programme across units of observation. The third group includes systematic reviews and meta-analyses.

The impact assessment of Ecuador's Bono de Desarrollo Humano (BDH) on school enrolment reported in Shady and Araujo (2006) fits into the first group. BDH was meant to have conditionalities similar to those of the Mexican CCT programme, Progresa. However, these conditionalities were never monitored or enforced via sanctions as originally planned. Nevertheless, administrators and local implementers emphasised the importance of school enrolment for programme participants during the implementation of the programme at the local level, and even television spots were used to spread this message. As a result, many

\footnotetext{
${ }^{7}$ Caldés, Coady and Maluccio (2006) suggest that in Mexico's Progresa programme the cost of conditionality monitoring is $24 \%$ of total administrative costs, which in turn represented $5.4 \%$ of total transfer costs.
} 
beneficiary families believed that children's school enrolment was required by the programme, while others were not aware of any conditionalities. The authors found that the beneficiaries who believed they should comply with education conditionalities to receive the benefits had an enrolment rate between 8.9 and 9.2 percentage points (pp) higher than those who did not.

De Brauw and Hoddinott (2008) also use a 'glitch' in the implementation of Mexico's Progresa, to assess the importance of conditionalities for its impact on school enrolment. During the implementation of Progresa, a significant group of beneficiaries did not receive a form needed to monitor the school attendance conditionality. For this group, the programme became, in effect, unconditional on school attendance. The authors found that the absence of the form led to a lower likelihood that children would attend school, compared with similar families who did receive the forms (around 7.2 pp lower) and that this reduction was more severe for the transition from primary to lower secondary school (up to sixth grade), whereby the likelihood of enrolment for children of non-monitored families was 16 pp lower than for monitored ones.

Both studies reached similar conclusions about the independent role of conditionalities. Obviously, strategies based on 'glitches' in the implementation of the conditionalities of CCT programmes do not yield a clear control group in the way that an experimental design does. In fact, Hanlon et al. (2010) suggest that the impacts these authors attribute to conditionalities could be due to differences between groups that thought conditions were in place and groups that did not, or otherwise could be an impact of cash transfers.

As for the second group of studies, namely those based on experimental studies, Baird et al. (2011) conducted a randomised controlled trial (RCT) for two years (2008-2009) in the district of Zomba, in Malawi, to test a variety of design features of cash transfer programmes, including the role of conditionalities. The target population of the cash transfer experiment comprised unmarried girls aged thirteen to twenty-two years. The 176 enumeration areas of the district were randomised into two groups: a treatment area in which cash transfers were implemented, and control areas with no cash transfer programme in place. In addition, the experiment varied by the school status of girls: for girls who were 
already enrolled in school at the start of the study, the cash transfer scheme was made conditional, unconditional, or not available in specific areas. For girls who had dropped out of school at the beginning of the experiment, the cash transfer was made conditional in all treatment areas. The evaluation assessed schooling outcomes, including enrolment, attendance, and learning, as well as early pregnancy and marriage. The authors found that the CCT treatment areas had better outcomes than the UCT treatment areas in terms of educational outcomes. Although both interventions led to a decrease in drop-out rates, the impact of the UCT programme corresponded to $43 \%$ of the impact of the CCT programme. In addition, the CCT impact also outperformed the UCT impact in tests of English reading comprehension.

Akresh et al. (2013) also used an RCT to assess the impact of conditionalities for the two-year Nahouri Cash Transfers Pilot Project, implemented in rural Burkina Faso. School enrolment, attendance, and learning were the outcomes of interest for this evaluation. The seventy-five villages in the Nahouri province that had a primary school were randomly assigned to five different groups of fifteen villagers: a control group that did not receive the benefits of the programme, two groups to whom the cash payment was conditional on school attendance, and differed only in terms of who received the transfer, the father or the mother, and two groups to whom the transfer was unconditional, and, again, differed only in terms of the cash transfer recipient. The target population of the programme comprised poor families with children aged zero to fifteen years. Their results suggest that, although both UCTs and CCTs had similar impacts on school outcomes for non-marginal children, 12.5 pp and $11.7 \mathrm{pp}$, respectively, the CCT outperformed the UCT in educational indicators for marginal children (e.g. girls, younger children, and children with lower abilities). In particular, the UCT had no impact on girls, and its impact was much lower for those not enrolled at the baseline -9 pp compared to the CCT's impact of $16 \mathrm{pp}$.

Robertson et al. (2013) investigated the impact of CCTs and UCTs on birth registration, vaccine uptake, and school attendance in RCT implemented in twelve sites in the Manicaland province in Zimbabwe between January 2010 and January 2011. The experiment was based on a sample of approximately four thousand 
households, with fifteen hundred household beneficiaries of a CCT, thirteen hundred households beneficiaries of a UCT, and twelve hundred households part of the control group. The authors found mixed evidence regarding the adoption of conditionalities in the region. They found significant impacts of cash transfers on school attendance, with similar impacts for both CCT and UCT versions for children aged six to twelve years $-7.6 \%$ and $7.2 \%$, respectively. However, somewhat larger impacts for the CCT version among children aged thirteen to seventeen years were found $-10.4 \%$ against $7.9 \%$ for the UCT version.

A criticism generally raised against results of experiments, particularly when based on pilots, is that they do not adequately represent large-scale programmes. Moreover, as pointed out by Baird et al. (2011), there is no such thing as 'ideal conditions' to conduct experiments about the effects of conditionalities. On the one hand, implementing CCTs and UCTs in very different localities allows any possibility of communication between beneficiaries of the two types of cash transfers to be ruled out, but then it would have to be accepted that results could be affected by the unobserved heterogeneity between localities and beneficiaries of both CCT and UCT versions. On the other hand, conducting the experiment in communities close to each other reduces the risk of unobserved heterogeneity but increases the possibility of beneficiaries of the two versions of the cash transfers talking to each other and occasionally getting confused about conditions, generating behavioural spill-over effects that would compromise the findings of the evaluation.

The growing literature comparing CCTs and UCTs is being scrutinised and assessed in systematic reviews such as Pellerano and Barca (2014) and Osterkamp (2014), as well as in meta-analyses such as in Baird et al. (2013). These studies are a step forward in conceptualising conditionalities as a continuum, which may not be adequately depicted by binary categories (CCTs/UCTs), as previously pointed out by Baird et al. (2013).

Baird et al. (2013) highlight that the level of enforcement makes an important difference when it comes to measuring the effects of conditionalities. On the one hand, their meta-regression analysis suggests that both UCTs and CCTs have had a positive and significant impact on school enrolment and that the difference in the impact of size between these two types of cash transfers was not statistically 
significant. On the other hand, when only CCTs with explicit and enforced conditions are included in the meta-analysis, differences in the impacts of size favouring CCTs - compared to UCTs - were larger and statistically significant. It is important to note, however, that neither CCTs nor UCTs have had any impact on learning.

Despite their extensive reviews, Pellerano and Barca (2014) and Osterkamp (2014) do not conduct a meta-analysis based on the estimates from other studies. Rather, they raise the issues that need to be taken into account when assessing whether it is sensible to choose CCTs - or, as Pellerano and Barca (2014) put it, to establish 'conditions for conditionalities'. Both studies argue that conditionalities should not be an option in the case of inadequate provision of public services and should be considered feasible only if demand-side barriers to the consumption of certain public services are rooted in "information, preferences, and power structures" (PELLERANO and BARCA, 2014, p. 14). However, while Pellerano and Barca (2014) claim that the success of CCTs in Latin America is grounded on a specific political environment and that further assessment based on the costs and benefits of adopting explicit conditionalities is necessary, Osterkamp suggests that studies are increasingly finding "significant and even considerable differences -favouring CCT schemes" (OSTERKAMP, 2014, p. 221).

Large literature reviews such as Baird et al. also have their limits, since programmes under analysis are designed and implemented in "a myriad of ways (...) not all of which (...) [are] observable to researchers or other policymakers" (BAIRD et al., 2013, p. 15). In other words, it is always possible in a meta-analysis to compare things that are not comparable. It seems clear that no particular study or methodology will give a definite answer to the question of whether conditionalities have an effect beyond the income effect. Rather, a conclusion may emerge from a large number of different studies, adopting different methodologies. In the following section, we present the strategy adopted in this paper to try to answer the question.

\section{An ecological approach to study the effects of conditionalities}

\section{Bolsa Família and conditionalities}

Bolsa Família is a conditional cash transfer programme, implemented by the Brazilian Ministry of Social Development (MDS). Conditional cash transfers are a 
kind of welfare benefit defined by certain features. They deliver cash rather than in-kind transfers; are family- and not individual-based; adopt targeting mechanisms to keep transfers limited to the poor; and, finally, they condition the transfers to specific behaviours by beneficiary families (such as school attendance of children and/or periodical visits to health services). Bolsa Família has a simple set of conditionalities attached to its cash transfers. School attendance rates need to be at least $85 \%$ for children aged six to fifteen years and $75 \%$ for adolescents aged sixteen to seventeen years. Children younger than seven years old need to have their nutrition status checked at least twice a year and to be vaccinated on time. Conditionalities also include pre- and post-natal monitoring.

Educational conditionalities have been part of the original design of Bolsa Família since its inception in 2003. Ministerial orders were published in 2004 and 2005 to coordinate different agencies and government levels to define their roles in conditionality monitoring. The complex process of conditionality monitoring was initially delegated to Caixa Econômica Federal (a public bank that works as the financial operator for the Programme) (LICIO, 2012), but the bank was not able to make it fully operational until 2006. The effective monitoring of these conditionalities began after pressure from the media and the Federal Court of Accounts. In 2006, the Ministry of Education, working together with Secretariats of Education at state and municipal levels, started collecting and processing data on school attendance (AGATTE, 2010).

Certain dimensions in the monitoring of educational conditionalities are relevant for this paper. The first is that this monitoring is based on a federative arrangement. Due to the perceived limited institutional capacities of municipalities, the relationship between the central and local governments in the context of Bolsa Família was hierarchical (LICIO, 2012), with the central government leading the process. Despite the central government's prominent role, "there is still room for decisions at the local level" (BICHIR, 2011, p. 25). Thus, it is natural that local governments perform differently for a variety of reasons. Second, the system was designed to reduce costs for beneficiary families. Families do not have to carry documentation to and from the school to certify their compliance with educational conditionalities. Information about their children (name, age, grade, school etc) 
comes from administrative records, organised by the federal government and sent electronically to all Brazilian municipalities. Local governments are in charge of monitoring conditionalities: they use this data to identify beneficiaries and collect attendance information from all schools in their municipalities (not only schools managed by the local government itself, but also schools managed by the state in the municipality). This demands coordination between municipalities and states, which is supported by the federal government. This information is relayed electronically to the federal government every two months. A consequence of this design is that there is an attrition rate that imposes limits on monitoring: administrative records are not always precise; children can move to a different school from the one initially recorded on the information database used by Bolsa Família - named Cadastro Único (Single Registry); and local governments face occasional difficulties locating them. The third dimension is that the sanctions for non-compliance are implemented gradually. If beneficiary children are not attending school, families first receive a warning letter; a second episode of non-compliance leads to a temporary blockage of the benefit ${ }^{8}$; from the third onwards, benefits are suspended ${ }^{9}$. In very specific situations, families may end up being excluded from the programme ${ }^{10}$. Administrative records from MDS suggest that only 45 per cent of all families who receive a warning letter about non-compliance and possible sanctions have their benefits blocked; and only 41 per cent have their benefits suspended. Currently, the number of permanent exclusions is negligible. What is relevant is that noncompliant families receive signals, at different levels, that the school attendance of their children is being monitored. These signals seem to be effective, since only a minority of families receive more serious sanctions ${ }^{11}$.

\footnotetext{
${ }^{8}$ Blockage: families cannot withdraw their benefit that month, but it will be available the following month along with that month's benefit.

${ }^{9}$ Suspension: families are still members of the programme, but they lose the benefit while noncompliance persists.

${ }^{10}$ Families can only be excluded from the programme after close monitoring by a social assistance team over a period of at least one year.

11Ministério do Desenvolvimento Social (2017). Table: Repercussões por descumprimento de Condicionalidades. Available at <http://aplicacoes.mds.gov.br/sagidata/misocial/tabelas/mi_social.php>. Accessed on January, 30, 2018.
} 
As shown in Figure 01, the monitoring of educational conditionalities for children aged six to fifteen years has increased over time and most recently covers about $90 \%$ of the beneficiaries at the national level.

Since Bolsa Família was implemented simultaneously in all Brazilians municipalities, it is impossible to assess its impacts on education and health outcomes comparing municipalities and/or schools using dichotomous variables, as in the case of most papers reviewed in the last section. However, recent papers such as Simões and Sabates (2014), Rasella et al. (2013), and Guanais (2013) have used ecological approaches to assess the overall impact of the programme on education and health-related outcomes. These models are estimated at the aggregate level, schools in the case of Simões and Sabates (2014) and municipalities in Rasella et al. (2013) and Guanais (2013). In all three papers, the 'treatment variable' is defined as the coverage of Bolsa Família for each observed unit (schools or municipalities). The key source of identification of the impact of Bolsa Família on final outcomes used in this approach is the variation of the programme's coverage across schools and municipalities and over time.

Figure 01. Monitoring of school attendance of Bolsa Família beneficiary children aged 6-15 at the national level (2008-2014)

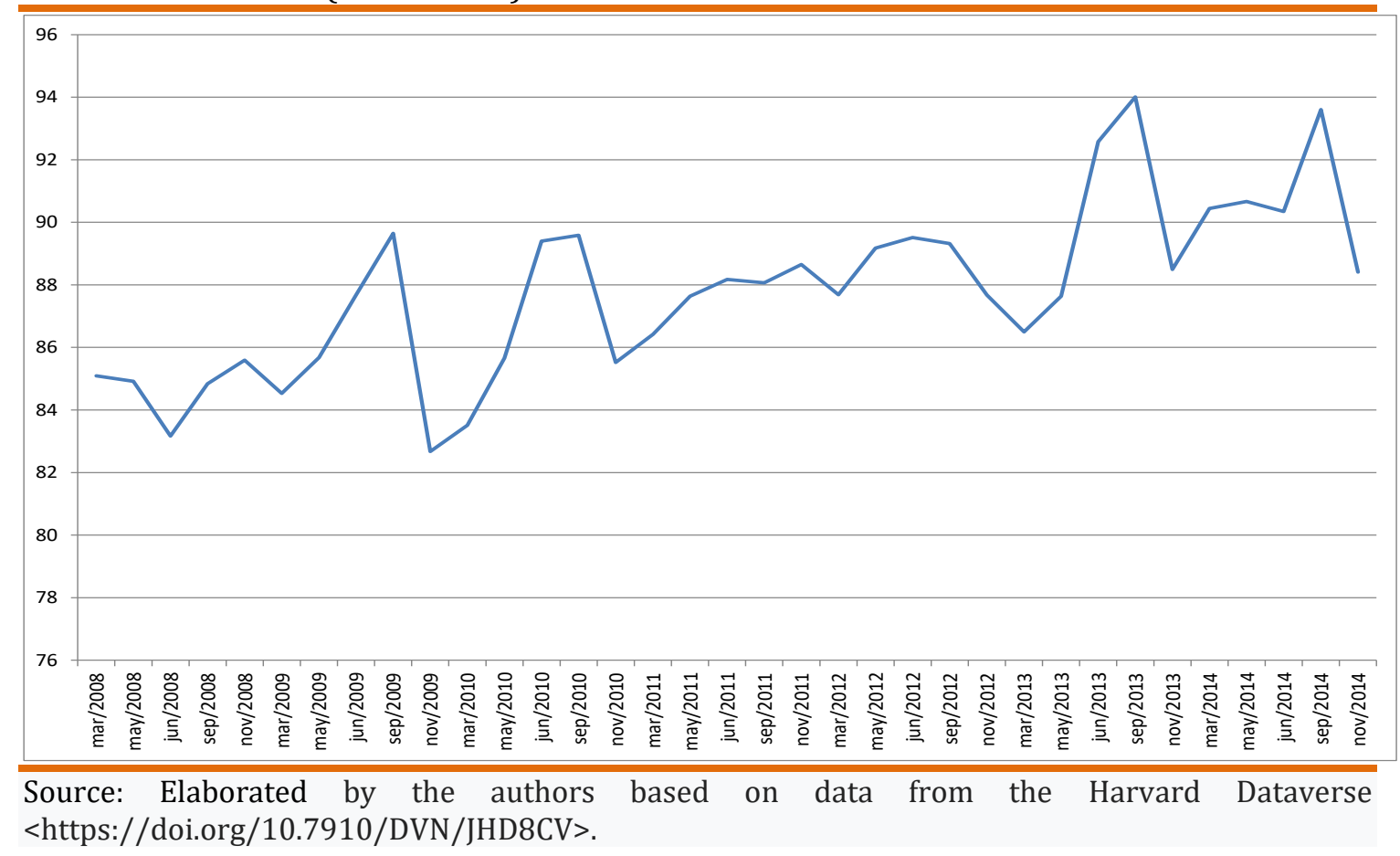


When attempting to measure the additional effect of conditionalities on educational and health outcomes, the papers reviewed in the previous sections often tried to compare three different groups: 01. a CCT treated group (transfers and conditionalities); 02. a UCT treated group (no conditionalities); and 03. a pure control group (no transfers). This identification strategy could not be adopted in this paper, since conditionalities-just like the Bolsa Família cash payments - were implemented simultaneously in all municipalities. However, conditionality monitoring (and consequently enforcement) varies across Brazilian municipalities, as does programme coverage. Thus, the rate of conditionality monitoring could be used as the 'treatment' variable to assess the effects of Bolsa Família on outcomes of interest at the municipal level.

Bolsa Família's coverage and rate of conditionality monitoring vary across municipalities because the programme is implemented in a decentralised manner (BICHIR, 2011; LICIO, 2012; LINDERT et al., 2007). Although the central government has a major role on how the Programme is implemented and defines the actions of local governments, municipalities are responsible for both registering potential beneficiary families and monitoring conditionalities. They decide which operative strategies to adopt and the amount of human and financial resources to employ in these tasks. In 2006, the Federal Government introduced a financial incentive for municipalities to improve their coverage and conditionality monitoring (FERNANDES, 2016a) but still held them responsible for setting the parameters for operation in their areas.

In such a context, municipalities with similar poverty rates can have different rates of coverage, and municipalities with similar coverage can have different levels of monitoring of conditionalities. In fact, the programme's coverage and rate of conditionality monitoring is very weakly correlated ${ }^{12}$. Therefore, it should be possible to compare the effects of different levels of monitoring and enforcement of conditionalities on educational and health indicators for municipalities with similar observable characteristics. Assuming that these two indicators - coverage and monitoring level - adequately proxy the two dimensions of the programme - cash payments and conditionalities, respectively

${ }^{12}$ The Pearson correlation is -0.016 . 
— it is then possible to estimate how much of the variation in the dependent variable is associated with the variation in these two dimensions of Bolsa Família.

\section{Methodology}

\section{Data}

Two indicators are used as dependent variables in the models presented in the next subsection - progression and drop-out rates, at the municipal level, for the basic level of education (nine years) in public schools (both local and State schools), covering the period from 2008 to 2012 . This period was defined in accordance with the model adopted to analyse the longitudinal data (growth model, presented later in this section). It requires 'centralised', time-invariant independent variables, which were extracted from the 2010 population census.

Both progression and drop-out rates are published by the National Institute for Educational Research (Instituto Nacional de Estudos e Pesquisas Educacionais INEP). Rates are computed at the municipality level for all students, not only for Bolsa Família beneficiaries. Figures 02 and 03 show their trajectory from 2008 to 2012. Over this period there was a considerable decrease in average drop-out rates, accompanied by an increase in average progression rates.

Figure 02. Average municipal drop-out rates by year, 2008-2012 (percentage)

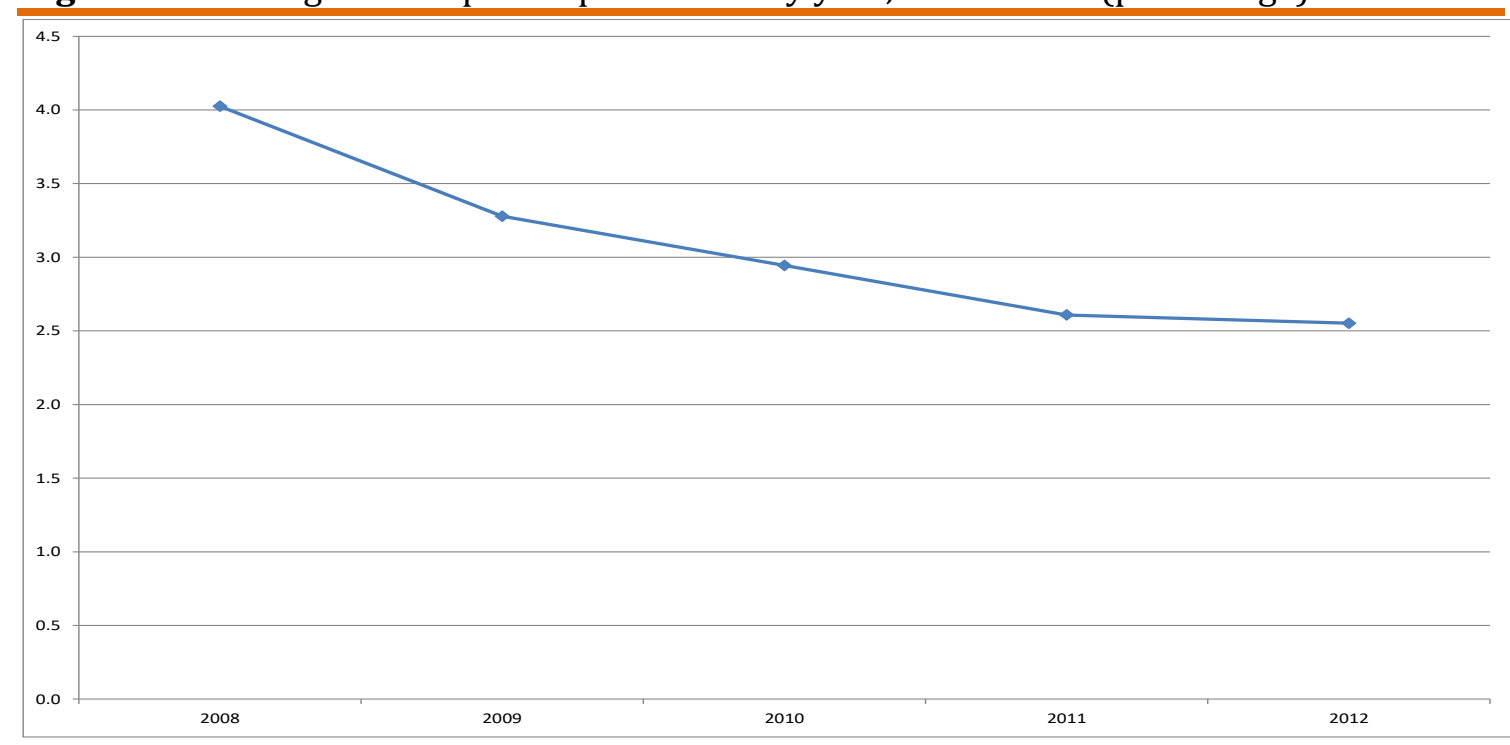

Source: Elaborated by the authors based on data from the Harvard Dataverse <https://doi.org/10.7910/DVN/JHD8CV>. 
Figure 03. Average municipal progression rates by year, 2008-2012 (percentage)

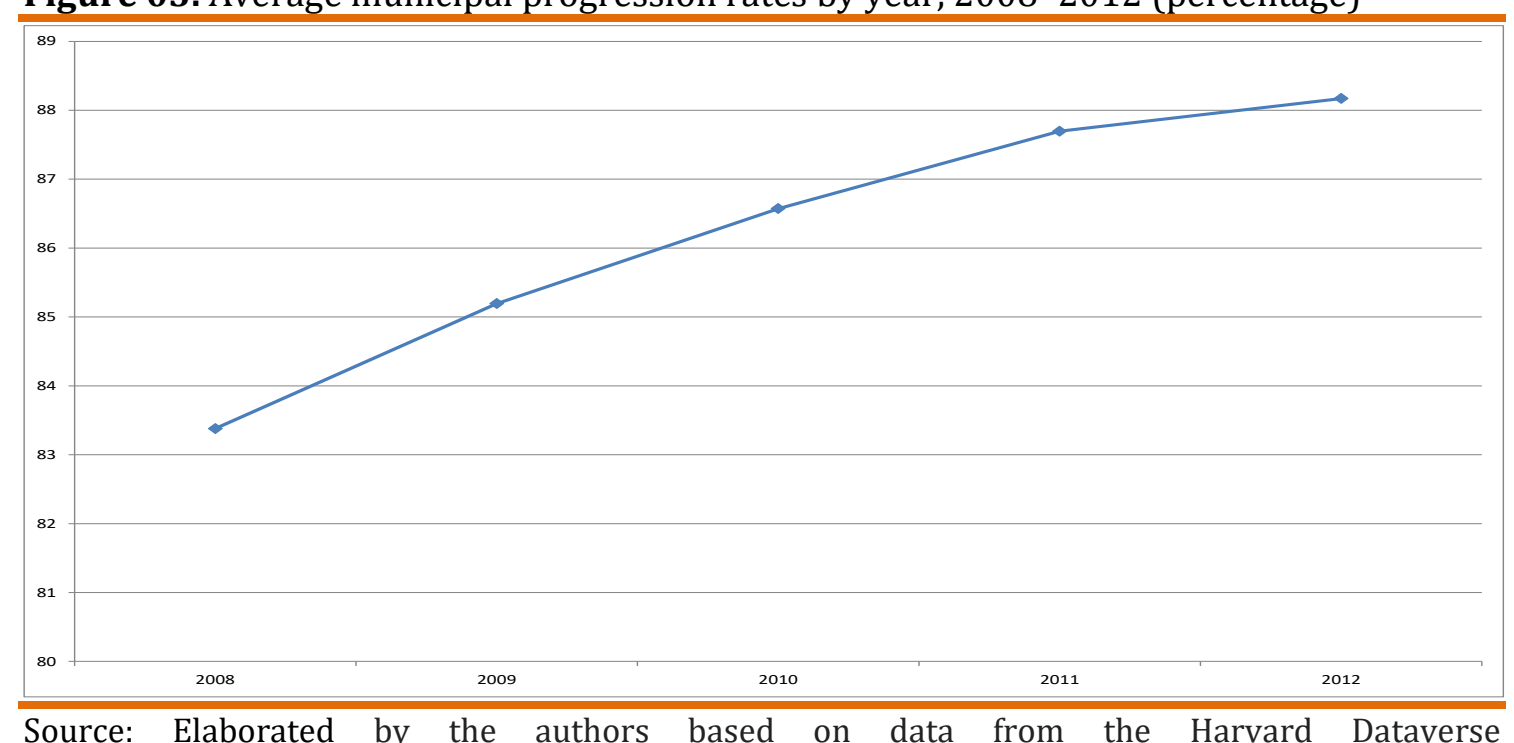

Source: Elaborated by the authors based on data from the Harvard Dataverse <https://doi.org/10.7910/DVN/JHD8CV>.

We assume that the dependent variables' variation and trajectory across municipalities can be explained by a set of predictors at the municipal level.

As for the two Bolsa Família treatment variables, programme coverage percentage of beneficiary families over the expected number of beneficiary families - proxies for the programme's cash transfer component, while the monitoring of school attendance for basic education (first nine years) - the percentage of beneficiary children in basic education who have their school attendance monitored - proxies for how binding conditionalities are.

The average coverage of Bolsa Família was calculated based on administrative data from May to December 2012. The expected number of beneficiaries is based on the sample of the 2010 Brazilian population census (made available in 2012). This sample is robust for general use at the municipal level. For small and relatively affluent municipalities, however, the sample size (the expected number of beneficiaries) tends to be small. This helps explain the existence of some cases of very high or low coverage rates. The quantitative analysis performed in this paper was also carried out with a dataset where outliers in this variable (z-score > 2.576) were removed, but results remained fundamentally the same and the authors decided to maintain the original dataset.

The monitoring of the rate of school attendance for basic education is the annual average for 2010 (for OLS models), or over 2008-2012 (for growth-curve 
models, see section below). Five times every year municipalities receive a list of students whose school attendance should be monitored (beneficiary children enrolled in basic education) and gives notice of who they were able to monitor. As with any administrative record, there are conflicting incentives for municipalities to either misreport or accurately report their monitoring rates ${ }^{13}$; however, administrative data on school attendance under Bolsa Família has been used in the literature (see, for instance, OLIVEIRA and SOARES, 2013).

Both treatment variables used administrative data from the MDS.

The time-invariant socio-economic situation of municipalities was measured using 2010 Brazilian population census data, carried out by the Brazilian Institute of Geography and Statistics (IBGE): 01. average household per capita income; 02. municipal Gini coefficient of per capita income; and 03. proportion of households with inadequate source of water and sewage discharge.

The geographical context of the municipality was measured by the following variables, also taken from the 2010 Brazilian population census: 01. geographical region of the municipality: North (449 municipalities, omitted); Northeast (1,794 municipalities); Southeast (1,668 municipalities); South (1,188 municipalities); and Centre-West (466 municipalities); 02. population size: Up to 5,000 inhabitants (omitted); 5,001 to 10,000; 10,001 to 20,000; 20,001 to 50,$000 ; 50,001$ to 100,$000 ; 100,001$ to 500,000 ; and above 500,000 inhabitants; and 03. proportion of rural population.

Previous educational attainment (or handicap) is measured by the percentage of the population aged 25 or more who are illiterate, also according to the 2010 Brazilian population census.

\footnotetext{
${ }^{13}$ Transfers to municipalities are partially affected by their monitoring of school attendance, so there is an incentive to over-report. At the same time, they do not report a mere overall rate: they have to report individual attendance, and this data is auditable by local social control boards and federal government auditors. Moreover, if a municipality decides to fabricate data (to avoid checking actual school attendance against local schools), it will also have to report that all students are adequately attending classes (otherwise their families will be penalised for not complying with conditionalities), which could result in an awkward report (where no student is non-complying), raising suspicion. In other words, it does not seem to be an unambiguous advantage for municipalities to misreport their level of school attendance monitoring.
} 
The management capacity of the local government is measured by the Index of Decentralised Management (IGD), developed by the MDS (annual average between 2008 and 2012) ${ }^{14}$.

\section{The models}

Two different models are reported in this paper to assess the associations between the two components of Bolsa Família - cash transfers and conditionalities - and drop-out and progression rates at the municipal level for students from the first to ninth grades.

The first one is a simple OLS regression model: $Y_{i}=b_{0}+b_{1} X_{i 1}+b_{2} X_{i 2}+\ldots+$ $b_{n} X_{i n}+\varepsilon_{i}$, where the dependent variable $\mathrm{Y}$ is a linear function of the predictors $\mathrm{X}_{n}$ discussed in the last subsection of this paper. In this cross-sectional model the dependent variables - drop-out rates and progression rates - as well as the independent conditionality monitoring variable use data for 2010 , in line with the other variables derived from the population census used in the analysis, which are all from $2010^{15}$. The descriptive statistics of all variables used in the model are presented in Table 01.

To exploit the panel data nature of the available information on the dependent variables, as shown in Figures 02 and 03, we use 'growth-curve' models (SINGER and WILLET, 2003) to assess the association between independent and dependent variables, not only on the initial level of the dependent variables but also on their trajectory over time. Growth-curve models are fundamentally a multi-level linear model where repeated observations over time (Level 01) are nested in specific entities (Level 02) - municipalities, in our case. It is a model that is composed of two sub-models, one modelling variation at Level 01, individual change over time, and another modelling systematic inter-individual heterogeneity in change (Level 02).

\footnotetext{
${ }^{14}$ The IGD is an index that measures the performance of municipalities with regards to keeping the information database used by Bolsa Família-the Single Registry-updated, as well as its performance in terms of monitoring both education and health conditionalities. For more information on the IGD, see Soares (2012).

${ }^{15}$ With the exception of the indicator for Bolsa Família coverage, which, as explained before, uses data from May to December 2012.
} 
Table 01. Descriptive statistics

\begin{tabular}{lllllllll}
\hline Variables & Obs. & Mean & $\begin{array}{l}\text { Std. } \\
\text { Dev. }\end{array}$ & Min. & Max. & p25 & p50 & p75 \\
\hline Drop-out (2010) & 5,563 & 2.94 & 2.61 & 0.00 & 23.34 & 0.99 & 2.24 & 4.20 \\
Progression (2010) & 5,563 & 86.57 & 7.37 & 52.24 & 100.00 & 81.62 & 87.48 & 92.38 \\
Attendance monitoring (\%) & 5,563 & 89.87 & 6.71 & 50.59 & 100.00 & 86.41 & 91.30 & 94.78 \\
BFP coverage (\%) & 5,563 & 106.07 & 23.62 & 13.53 & 344.90 & 93.88 & 107.87 & 119.81 \\
Illiterate 25 years old + (\%) & 5,563 & 20.52 & 12.77 & 1.10 & 57.18 & 9.98 & 16.46 & 31.34 \\
IGD (0-100) & 5,563 & 80.36 & 8.90 & 31.50 & 97.83 & 74.92 & 81.67 & 87.08 \\
Per capita income (in Brazilian & 5,563 & 493.62 & 243.31 & 96.25 & 2043.74 & 281.05 & 467.65 & 650.67 \\
reais-BRL) & & & & & & & & \\
Gini coefficient & 5,563 & 0.49 & 0.07 & 0.28 & 0.80 & 0.45 & 0.49 & 0.54 \\
Households with inadequate & 5,563 & 9.20 & 12.84 & 0.00 & 85.36 & 0.53 & 3.27 & 13.05 \\
water/sewage (\%) & & & & & & & & \\
Number of inhabitants, cat. 1 & 5,563 & 0.22 & 0.41 & 0.00 & 1.00 & - & - & - \\
Number of inhabitants, cat. 2 & 5,563 & 0.25 & 0.43 & 0.00 & 1.00 & - & - & - \\
Number of inhabitants, cat. 3 & 5,563 & 0.19 & 0.39 & 0.00 & 1.00 & - & - & - \\
Number of inhabitants, cat. 4 & 5,563 & 0.06 & 0.23 & 0.00 & 1.00 & - & - & - \\
Number of inhabitants, cat. 5 & 5,563 & 0.04 & 0.21 & 0.00 & 1.00 & - & - & - \\
Number of inhabitants, cat. 6 & 5,563 & 0.01 & 0.08 & 0.00 & 1.00 & - & - & - \\
Northeast region & 5,563 & 0.32 & 0.47 & 0.00 & 1.00 & - & - & - \\
Southeast region & 5,563 & 0.30 & 0.46 & 0.00 & 1.00 & - & - & - \\
South region & 5,563 & 0.21 & 0.41 & 0.00 & 1.00 & - & - & - \\
Centre-West region & 5,563 & 0.08 & 0.28 & 0.00 & 1.00 & - & - & - \\
Rural population (\%) & 5,563 & 36.16 & 22.04 & 0.00 & 95.82 & 17.79 & 35.33 & 52.92 \\
\hline
\end{tabular}

Source: Elaborated by the authors based on data from the Harvard Dataverse $<$ https://doi.org/10.7910/DVN/JHD8CV>.

The level 01 sub-model can be expressed as in (1): $Y_{i j}=\pi_{0 i}+\pi_{1 i}\left(T I M E_{i j}\right)+\varepsilon_{i j}$ (1) which assumes a linear trajectory over time $j$ for the dependent variable $Y$, for each entity or individual $i$.

In the Level 02 sub-model, the Level 01 parameters become dependent variables. The individual growth parameters $\pi 0$ (intercepts) and $\pi_{1 i}$ (the slopes or rates of change) of the Level 01 sub-model are regressed on a set of time-invariant predictors $(X)$ that are considered relevant to explain the intercepts (initial status) and the growth trajectory (rate of change). Thus, $\pi_{0 i}=\Upsilon_{00}+\Upsilon_{01} X_{i}+\zeta_{0 i}$ and $\pi_{1 i}=\Upsilon_{10}$ $+Y_{11} X_{i}+\zeta_{1 i}$

These two sub-models can be collapsed: $Y_{i j}=\left(Y_{00}+Y_{01} X_{i}+\zeta_{0 i}\right)+\left(Y_{10}+\Upsilon_{11} X_{i}\right.$ $\left.+\zeta_{1 i}\right)\left(T I M E_{i j}\right)+\varepsilon_{i j}$ generating the composite model $Y_{i j}=\left[\Upsilon_{00}+Y_{10}\left(T I M E_{i j}\right)+\Upsilon_{01} X_{i}+\right.$ $\left.\Upsilon_{11}\left(X_{i} \times T I M E_{i j}\right)\right]+\left[\zeta_{0 i}+\zeta_{1 i}\left(T I M E_{i j}\right)+\varepsilon_{i j}\right]$.

The dependent variable $Y$ depends simultaneously on the effect of Level 01 predictor TIME and Level 02 predictor(s) $X$, including the interaction between them.

Using a growth-curve model is advantageous compared to a simple OLS regression, as it considers the longitudinal pattern of the dependent variables. 
Predictors $\mathrm{X}_{n}$ can account for differences between individuals (or, as in our case, municipalities) during their intercepts (initial status), but also for differences between them in their trajectories (that is, in their slopes or rates of change).

\section{Results}

\section{OLS regression}

The OLS regression model fitted to explain the variation in drop-out rates presents somewhat expected results (see Table 02). Drop-out rates seem to be especially affected by the previous educational attainment of the municipality (percentage of the population aged twenty-five or more who are illiterate). The management capacity of the local government was associated with drop-out rates as expected: the higher the management capacity the lower the drop-out rate.

Table 02. OLS regression model — drop-out rates

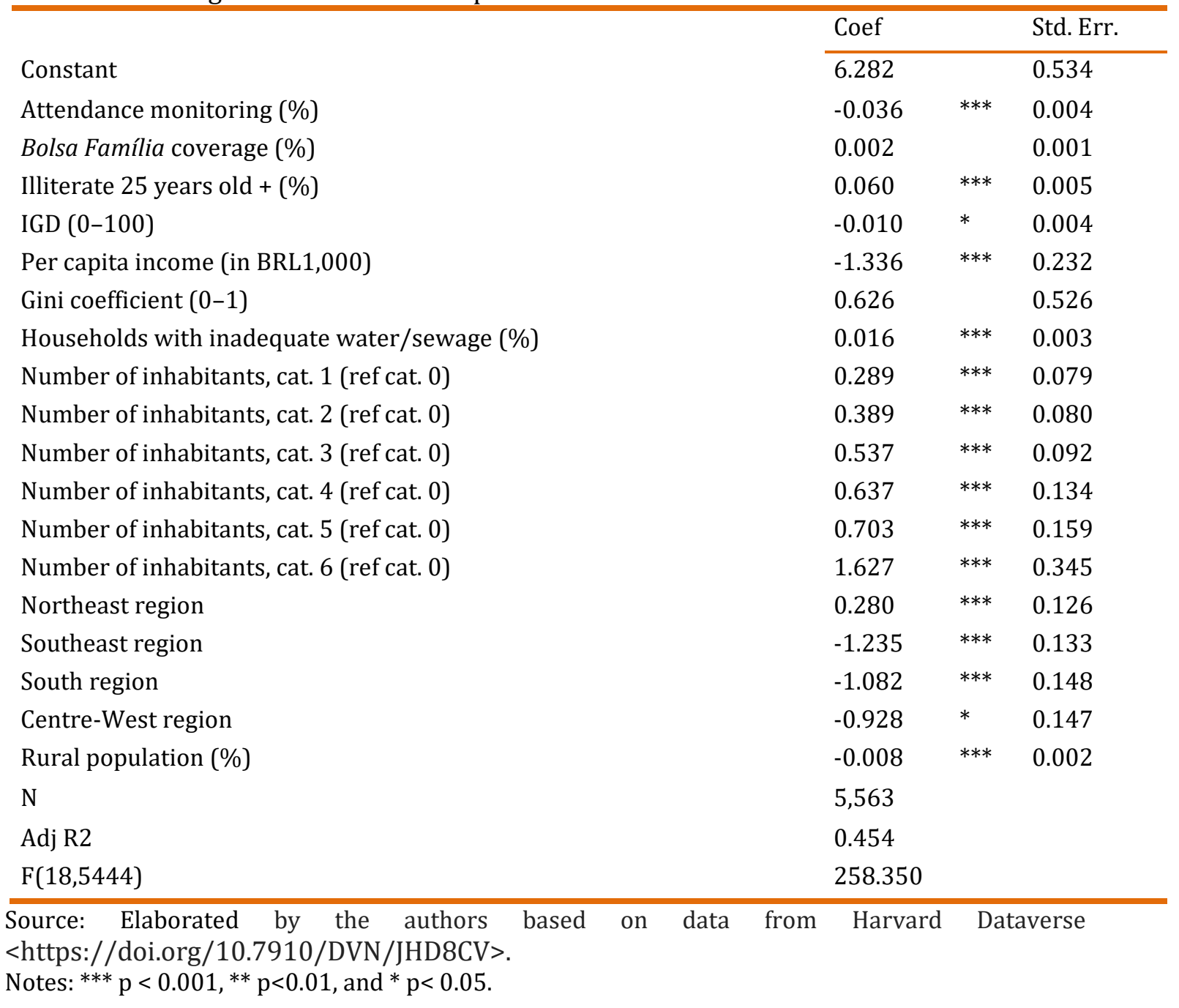


Estimates for socio-economic independent variables also had the expected sign. An increase in the per capita income of the municipalities was associated with lower drop-out rates. An increase in the percentage of households with an inadequate source of water or sewage discharge was associated with an increase in drop-out rates.

In relation to geographic variation, the larger the population of the municipality, the higher its drop-out rate. A typical city of five hundred thousand inhabitants or more would have a drop-out rate $1.63 \mathrm{pp}$ higher than the average town of five thousand inhabitants or less. Drop-out rates were also higher in municipalities located in the Northeast and North regions than in those located in the southern regions of the country. Perhaps the only unexpected result was the negative association between drop-out rates and the proportion of rural population in the municipality.

Bolsa Família-related variables show interesting results. Unexpectedly, coverage (proxying cash transfers) does not seem to be negatively associated with drop-out rates: its estimate is not statistically significant at the $5 \%$ level.

On the other hand, the monitoring of school attendance, as expected, was negatively associated with drop-out rates. For a hypothetical 'average' municipality (with an attendance monitoring of 90\%), the predicted drop-out rate would be 3.2 pp lower than if it had none at all.

The OLS regression model fitted to explain the variation of school progression across Brazilian municipalities shows similar results (Table 03).

Educational attainment (the percentage of illiterate people aged twentyfive and over) was negatively associated with progression rates. The management capacity of the local government was positively associated with the progression rate. Municipal-level income and the Gini coefficient were associated with school progression rates in the expected direction: positive and negative, respectively. The percentage of households with an inadequate source of water or sewage discharge was not associated with progression rate.

Independent variables related to the geographical context of the municipality also presented expected results. The larger the municipality size (population), the lower the progression: all covariates controlled, a municipality 
with more than five hundred thousand inhabitants had a progression rate $4.1 \mathrm{pp}$ lower than a municipality with five thousand inhabitants or fewer. Municipalities in the Northeast region were associated with the lowest level of progression (3 pp lower than municipalities in the North region).

Table 03. OLS regression model-progression

\section{Constant}

Attendance monitoring (\%)

Bolsa Família coverage (\%)

Illiterate 25 years old $+(\%)$

IGD (0-100)

Per capita income (in BRL1,000)

Gini coefficient (0-1)

Households with inadequate water/sewage (\%)

Number of inhabitants, cat. 1 (ref cat. 0 )

Number of inhabitants, cat. 2 (ref cat. 0 )

Number of inhabitants, cat. 3 (ref cat. 0 )

Number of inhabitants, cat. 4 (ref cat. 0)

Number of inhabitants, cat. 5 (ref cat. 0 )

Number of inhabitants, cat. 6 (ref cat. 0 )

Northeast region

Southeast region

South region

Centre-West region

Rural population (\%)

$\mathrm{N}$

Adj R2

$\mathrm{F}(18,5444)$

\begin{tabular}{rrr}
\multicolumn{1}{c}{ Coef } & Std. Err. \\
\hline 76.565 & & 1.608 \\
0.098 & $* * *$ & 0.013 \\
-0.006 & & 0.004 \\
-0.076 & $* * *$ & 0.015 \\
0.064 & $* * *$ & 0.013 \\
5.439 & $* * *$ & 0.698 \\
-10.012 & $* * *$ & 1.582 \\
-0.009 & & 0.009 \\
-0.487 & $*$ & 0.237 \\
-0.431 & & 0.242 \\
-0.773 & $* *$ & 0.278 \\
-1.268 & $* *$ & 0.404 \\
-2.230 & $* * *$ & 0.478 \\
-4.116 & $* * *$ & 1.039 \\
-3.145 & $* * *$ & 0.380 \\
3.365 & $* * *$ & 0.400 \\
0.861 & $* * *$ & 0.445 \\
2.611 & $* * *$ & 0.441 \\
0.020 & $* * *$ & 0.005 \\
5,563 & & \\
0.380 & & \\
190.010 &
\end{tabular}

Source: Elaborated by the authors based on data from Harvard Dataverse $<$ https://doi.org/10.7910/DVN/JHD8CV>.

Notes: ${ }^{* *} \mathrm{p}<0.001,{ }^{* *} \mathrm{p}<0.01$, and ${ }^{*} \mathrm{p}<0.05$.

Bolsa Família coverage was not associated with school progression. On the other hand, attendance monitoring was positively associated with school progression. For a hypothetical 'average' municipality (with an attendance monitoring of 90\%), the predicted progression was $8.8 \mathrm{pp}$ higher than if it had no attendance monitoring at all.

\section{Growth-curve models}

Eight models were fitted for each of the dependent variables, gradually incorporating covariates and comparing their fit. Traditionally in growth-curve models, the first is the unconditional means model, which presents the mean value 
of the dependent variable for the period considered (here, 2008-2012) in level 02 and the residuals, both within individuals (that is, municipalities) (Level 01) and between municipalities (Level 02). Deviation from the mean is concentrated at Level 02 (between municipalities). The intra-class correlation (Level 02 deviation/Level 02 + Level 01 deviation) is over $75 \%$ for both dependent variables. As a result, at Level 01, for models from 02 to 08 we have opted to fit the simplest possible linear model, using only the time variable as suggested by Singer and Willet (2003).

Model 02 is the simplest growth model. It considers only the time variable at both levels, which allows us to check the overall tendency over time for the dependent variable. Drop-out rates decreased by 0.4 pp per year, and progression increased by 1.2 pp per year between 2008 and 2012. Compared to Model 01, the variance components of Model 02 incorporate two new parameters: Level 02 variance in rate of change and covariance between residuals of initial status and residuals of rate of change, both at Level 01 . The covariance between intercepts and rates of change, in the case of drop-out rates and progression, can be used to assess whether there is any tendency for dispersion or convergence in the observed values of the dependent variable over time. The goodness of fit of each model is given by Akaike's Information Criterion (AIC) and the Bayesian Information Criterion (BIC), both based on the log-likelihood.

Model 03 fitted for drop-out rates (see Table 04) points to uncontrolled effects of Bolsa Família (coverage and attendance monitoring). From Model 04 onwards, all covariates considered in the OLS model are gradually introduced to explain variation both in the initial status and in the rate of change of the dependent variable. Model 08 had the best fit among the models considered here to account for drop-out rates, according to the AIC and BIC.

The parameters of the fixed-effect portion of the model can be interpreted as usual, but with reference to intercepts and slopes of the models fitted at level 01 - i.e. the individual (municipal) level.

The association between Bolsa Família coverage and the initial status of drop-out rates is similar to the results found in the OLS regression model. Attendance monitoring was negatively associated with the initial status of drop-out 
rates (the higher the attendance monitoring, the lower the initial status of dropout rates). In Model 08, for a hypothetical municipality (with the average attendance monitoring of 90\%), the predicted initial status of drop-out rate was $5.6 \mathrm{pp}$ lower than if it had no attendance monitoring at all. Bolsa Família coverage, however, does not have a statistically significant association with the initial status of drop-out rates.

Educational attainment (the percentage of those aged twenty-five years or older who are illiterate) was positively associated with the initial status of drop-out rates. The management capacity of local administration (proxied by the IGD) was negatively associated with the drop-out rates. Estimates for socio-economic indicators had the expected sign. As per capita income increased, predicted initial status of drop-out rate decreased. The Gini coefficient was positively associated with the initial status of the dependent variable. The proportion of households with an inadequate source of water or sewage discharge was positively associated with the initial status of drop-out rates.

The proportion of rural population was negatively associated with the initial status of drop-out rates, as found in OLS models. The predicted initial status of drop-out rates was also higher in more populated cities.

As shown in Figure 02, drop-out rates decreased between 2008 and 2012. The predicted basic slope in Model 8 was -0.9 pp per year. Covariance between residuals of intercepts and of slopes at Level 01 was negative, thus there is a tendency for municipalities with higher initial status to have steeper slopes. This is 'compatible with a general tendency of convergence in drop-out rates across municipalities' over the period 2008-2012. In our models, variables associated with higher initial status of drop-out rates were also associated with steeper slopes and vice versa.

For instance, Bolsa Família coverage was not associated with the rate of change of drop-out rates, but attendance monitoring was positively associated with this rate. Although municipalities with higher levels of monitoring had lower levels of drop-out rates on the initial status, they also tended to reduce their drop-out rates more slowly. 
Table 04. Growth-curve models for drop-out rates

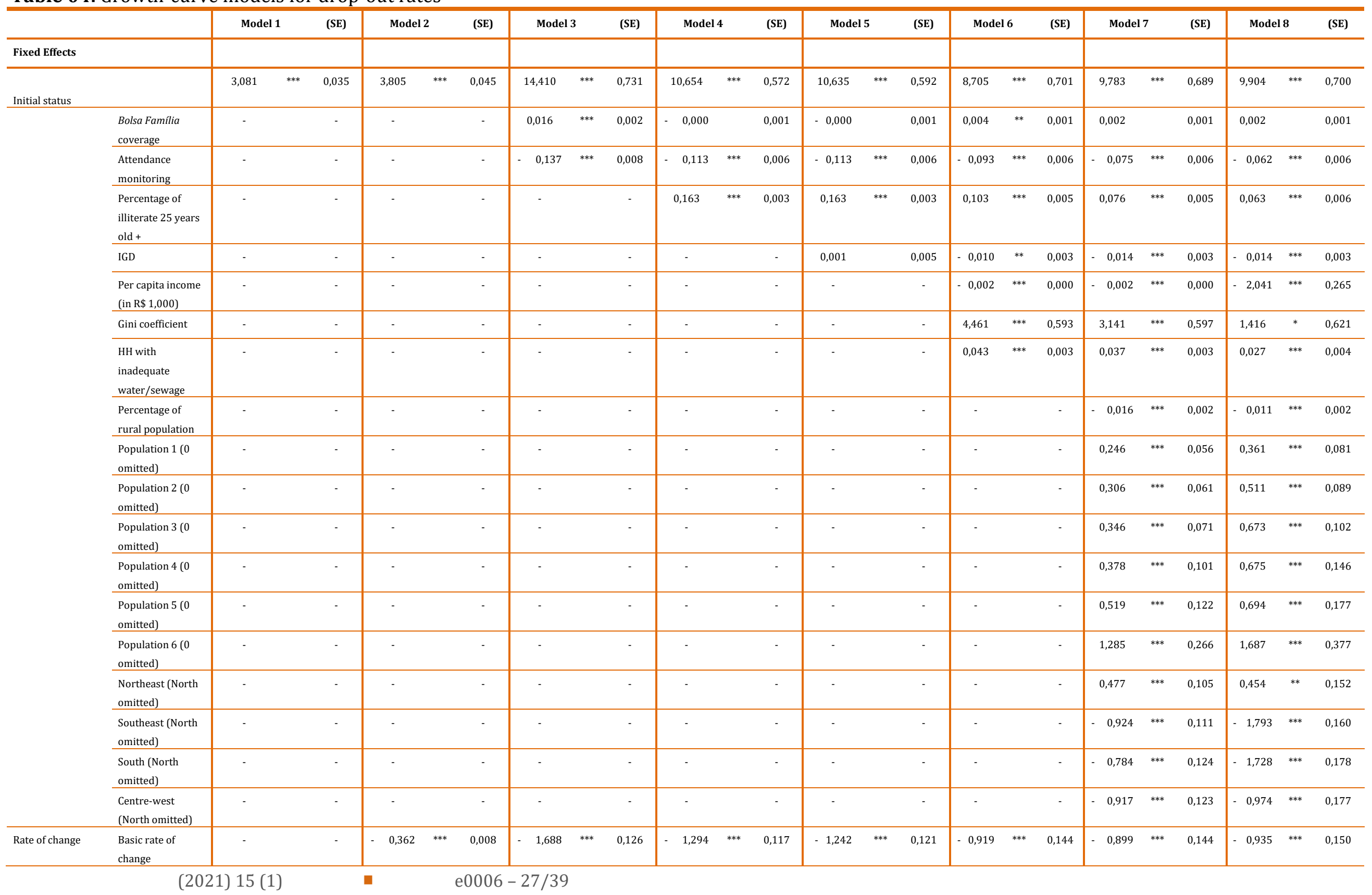


bpsr

\begin{tabular}{|c|c|c|c|c|c|c|c|c|c|c|c|c|c|c|c|c|c|c|c|c|c|c|c|}
\hline & $\begin{array}{l}\text { Bolsa Família } \\
\text { coverage \# year }\end{array}$ & - & - & - & - & - 0,002 & ${ }^{* * *}$ & 0,000 & 0,000 & & 0,000 & 0,000 & & 0,000 & $-0,000$ & & 0,000 & - 0,000 & & 0,000 & - 0,000 & & 0,000 \\
\hline & $\begin{array}{l}\text { Attendance } \\
\text { monitoring \# year }\end{array}$ & - & - & - & - & 0,017 & *** & 0,001 & 0,014 & $* * *$ & 0,001 & 0,015 & $* * *$ & 0,001 & 0,012 & $* * *$ & 0,001 & 0,010 & $* * *$ & 0,001 & 0,007 & $* * *$ & 0,001 \\
\hline & $\begin{array}{l}\text { Percentage of } \\
\text { illiterate } 25+\# \\
\text { year }\end{array}$ & - & - & - & - & - & & - & - 0,017 & $* * *$ & 0,001 & - 0,017 & $* * *$ & 0,001 & $-0,007$ & $* * *$ & 0,001 & - 0,008 & $* * *$ & 0,001 & 0,004 & ${ }^{* *}$ & 0,001 \\
\hline & IGD \# year & & & & & & & & & & & - 0,002 & & 0,001 & - & & - & - & & - & - & & - \\
\hline & $\begin{array}{l}\text { Per capita } \\
\text { income( } \mathrm{R} \$ \\
1,000) \# \text { year }\end{array}$ & - & - & - & - & - & & - & - & & - & - & & - & 0,314 & $* * *$ & 0,051 & 0,363 & $* * *$ & 0,052 & 0,272 & $* *$ & 0,057 \\
\hline & $\begin{array}{l}\text { Gini coefficient \# } \\
\text { year }\end{array}$ & - & - & - & - & - & & - & - & & - & - & & - & $-0,801$ & $* * *$ & 0,123 & - 0,832 & *** & 0,123 & 0,316 & ${ }^{*}$ & 0,133 \\
\hline & $\begin{array}{l}\text { HH with } \\
\text { inadequate } \\
\text { water/sewage \# } \\
\text { year }\end{array}$ & - & - & - & - & - & & - & - & & - & - & & - & $-0,005$ & $* * *$ & 0,001 & - 0,006 & *** & 0,001 & - 0,003 & $* * *$ & 0,001 \\
\hline & $\begin{array}{l}\text { Percentage of } \\
\text { rural population \# } \\
\text { year }\end{array}$ & - & - & - & - & - & & - & - & & - & - & & - & - & & - & 0,002 & $* * *$ & 0,000 & 0,000 & & 0,000 \\
\hline & $\begin{array}{l}\text { Population \# year } \\
(0 \text { omitted })\end{array}$ & & & & & & & & & & & & & & & & & & & & & & \\
\hline & 1 \# year & - & - & - & - & - & & - & - & & - & - & & - & - & & - & - & & - & $-0,035$ & & 0,020 \\
\hline & 2 \# year & - & - & - & - & - & & - & - & & & - & & - & - & & & - & & - & $-0,063$ & ${ }^{* * *}$ & 0,021 \\
\hline & 3 \# year & - & - & - & - & - & & - & - & & - & - & & - & - & & - & - & & - & 0,100 & $* * *$ & 0,024 \\
\hline & 4 \# year & - & - & - & - & - & & - & - & & - & - & & - & - & & - & - & & - & - 0,091 & $* *$ & 0,034 \\
\hline & 5 \# year & - & - & - & - & - & & - & - & & - & - & & - & - & & - & - & & - & 0,045 & & 0,041 \\
\hline & $6 \#$ year & - & - & - & - & - & & - & - & & - & - & & - & - & & - & - & & - & 0,128 & & 0,087 \\
\hline & $\begin{array}{l}\text { Region \# year } \\
\text { (North omitted) }\end{array}$ & & . & & & & & & & & & & & & & & & & & & & & \\
\hline & Northeast \# year & - & - & - & - & - & & - & - & & - & - & & - & - & & - & - & & - & 0,007 & & 0,033 \\
\hline & Southeast \# year & - & - & - & - & - & & - & - & & - & - & & - & - & & - & - & & - & 0,259 & *** & 0,034 \\
\hline & South \# year & - & - & - & - & - & & - & - & & - & - & & - & - & & - & - & & - & 0,282 & $* * *$ & 0,038 \\
\hline & $\begin{array}{l}\text { Centre-west \# } \\
\text { year }\end{array}$ & - & - & - & - & - & & - & - & & - & - & & - & - & & - & - & & - & 0,018 & & 0,038 \\
\hline $\begin{array}{l}\text { Varianc } \\
\text { compon }\end{array}$ & & & & & & & & & & & & & & & & & & & & & & & \\
\hline Level 1 & Within entity & 2,003 & 0,019 & 1,155 & 0,013 & 1,155 & & 0,013 & 1,155 & & 0,013 & 1,155 & & 0,013 & 1,155 & & 0,013 & 1,155 & & 0,013 & 1,155 & & 0,013 \\
\hline
\end{tabular}

(2021) 15 (1)

e0006-28/39 
bpsr

\begin{tabular}{|c|c|c|c|c|c|c|c|c|c|c|c|c|c|c|c|c|c|}
\hline Level 2 & In initial Status & 6,251 & 0,126 & 10,611 & 0,214 & 9,868 & 0,200 & 5,697 & 0,122 & 5,698 & 0,122 & 5,295 & 0,114 & 4,815 & 0,106 & 4,724 & 0,103 \\
\hline & In rate of change & - & - & 0,209 & 0,006 & 0,198 & 0,006 & 0,152 & 0,005 & 0,152 & 0,005 & 0,143 & 0,005 & 0,142 & 0,005 & 0,135 & 0,005 \\
\hline & Covariance & - & - & 1,255 & 0,033 & 1,168 & 0,031 & - 0,730 & 0,022 & $\begin{array}{l}-0,730 \\
\end{array}$ & 0,022 & $-0,671$ & 0,021 & 0,636 & 0,020 & 0,609 & 0,019 \\
\hline AIC & & 113834,8 & & 105145,4 & & 104766,9 & & 101748,1 & & 101746,6 & & $101387, \varepsilon$ & & 100883,2 & & 100738,6 & \\
\hline BIC & & 113859,5 & & 105194,8 & & 104849,2 & & 101846,9 & & 101861,9 & & 101544,2 & & 101138,4 & & 101076,2 & \\
\hline
\end{tabular}

Source: Elaborated by the authors based on data from Harvard Dataverse <https://doi.org/10.7910/DVN/JHD8CV $>$.

Notes: ${ }^{*} \mathrm{p}<0.05,{ }^{* *} \mathrm{p}<0.01{ }^{* * *} \mathrm{p}<0.001$

Model 1 - Unconditional means model

Model 2 - Unconditional growth model

Model 3 - Uncontrolled effects of BFP

Model 4 - Controlled effects of BFP by the "educational past"

Model 5 - Controlled effects of BFP by the "educational past" and quality of local public management

Model 6 - Controlled effects of BFP by the "educational past", quality of local public management and socioeconomic indicators

Modelss7 and 8 - Controlled effects of BFP'by the "educational past", quality of local public management, socioeconomic indicators and geographical covariates 
Table 05. Growth-curve models for progression

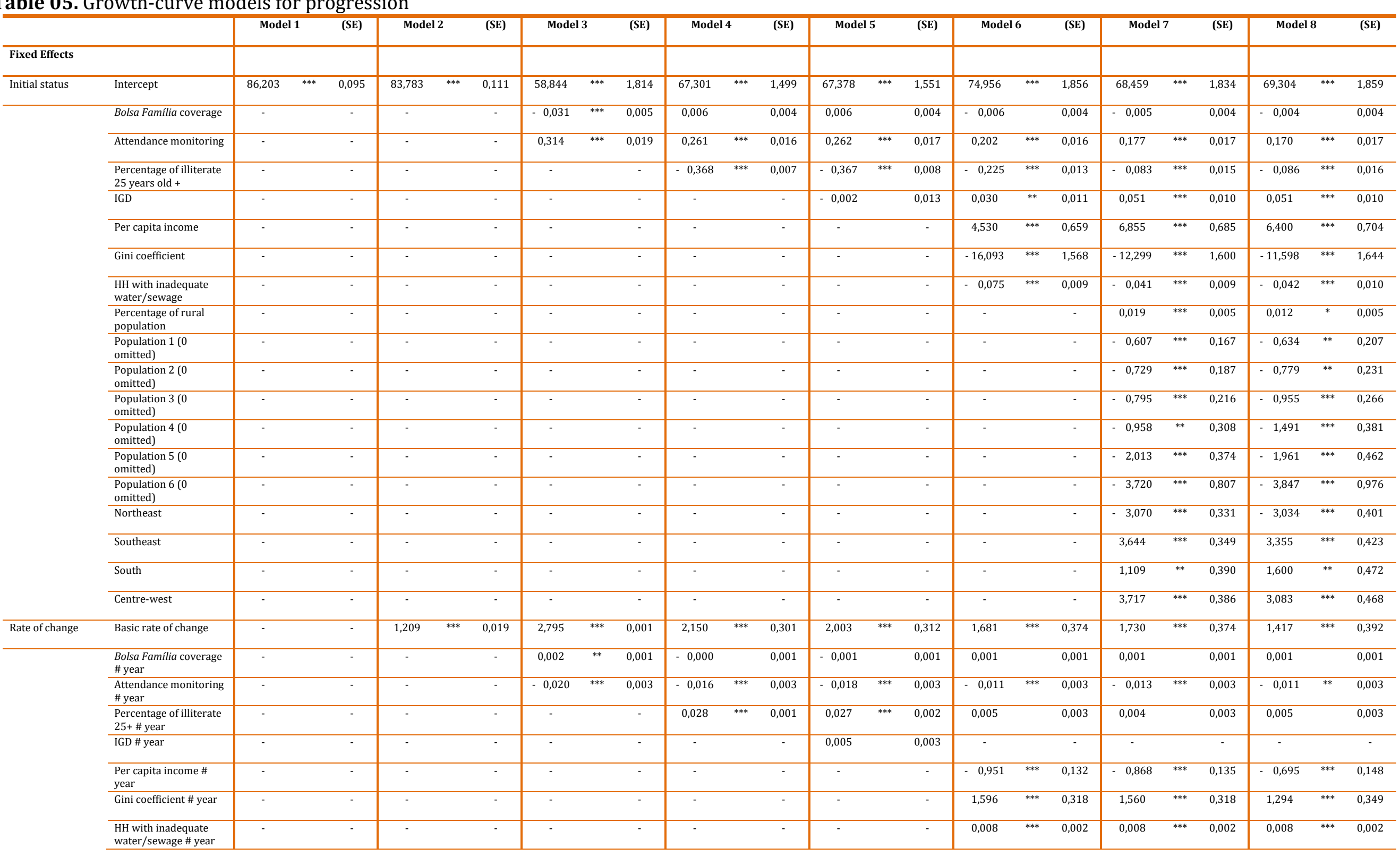




\begin{tabular}{|c|c|c|c|c|c|c|c|c|c|c|c|c|c|c|c|c|c|c|}
\hline & \multicolumn{3}{|c|}{ bpsr } & \multicolumn{15}{|c|}{ Luis Henrique Paiva, Fábio Veras Soares, Iara Azevedo Vitelli Viana, Flavio Cireno, Ana Clara Duran } \\
\hline & $\begin{array}{l}\text { Percentage of rural } \\
\text { population \# year }\end{array}$ & - & - & - & - & & - & - & - & & & - & - & 0,003 & $\begin{array}{ll}* * * & 0,001\end{array}$ & 0,005 & *** & 0,001 \\
\hline & $\begin{array}{l}\text { Population \# year ( } 0 \\
\text { omitted) }\end{array}$ & & & & & & & & & & & & & & & & & \\
\hline & 1 \# year & & & & & & & & & & & & & & & 0,008 & & 0,053 \\
\hline & $2 \#$ year & & & & & & & & & & & & & & & 0,016 & & 0,055 \\
\hline & 3 \# year & & & & & & & & & & & & & & & 0,062 & & 0,062 \\
\hline & 4 \# year & & & & & & & & & & & & & & & 0,211 & * & 0,091 \\
\hline & 5 \# year & & & & & & & & & & & & & & & 0,042 & & 0,107 \\
\hline & 6 \# year & & & & & & & & & & & & & & & 0,058 & & 0,232 \\
\hline & $\begin{array}{l}\text { Region \# year (North } \\
\text { omitted) }\end{array}$ & & & & & & & & & & & & & & & & & \\
\hline & Northeast \# year & & & & & & & & & & & & & & & - 0,013 & & 0,086 \\
\hline & Southeast \# year & & & & & & & & & & & & & & & 0,109 & & 0,090 \\
\hline & South \# year & & & & & & & & & & & & & & & - 0,185 & & 0,101 \\
\hline & Centre-west \# year & & & & & & & & & & & & & & & 0,239 & * & 0,100 \\
\hline \multicolumn{19}{|c|}{$\begin{array}{l}\text { Variance } \\
\text { components }\end{array}$} \\
\hline Level 1 & Within entity & 13,692 & 0,130 & 7,010 & 0,077 & 7,010 & 0,077 & 7,011 & 0,077 & 7,011 & 0,077 & 7,012 & 0,077 & 7,012 & 0,077 & 7,013 & & 0,077 \\
\hline \multirow[t]{3}{*}{ Level 2} & In initial Status & 47,366 & 0,950 & 64,553 & 1,305 & 60,854 & 1,235 & 39,689 & 0,834 & 39,691 & 0,834 & 37,423 & 0,791 & 33,801 & 0,724 & 33,690 & & 0,721 \\
\hline & In rate of change & - & - & 1,213 & 0,037 & 1,196 & 0,037 & 1,071 & 0,035 & 1,070 & 0,035 & 1,031 & 0,034 & 1,029 & 0,034 & 1,013 & & 0,034 \\
\hline & Covariance & - & - & $-5,172$ & 0,178 & $-4,925$ & 0,172 & $-3,299$ & 0,135 & $-3,299$ & 0,135 & $-3,016$ & 0,130 & $-3,184$ & 0,126 & $-3,142$ & & 0,125 \\
\hline AIC & & 167810,7 & & 158058,1 & & 157744,3 & & 155502,1 & & 155501,9 & & 155198,1 & & 154323,6 & & 154293,9 & & \\
\hline BIC & & 167835,4 & & 158107,5 & & 157826,7 & & 155600,9 & & 155617,2 & & 155354,5 & & 154578,8 & & 154631,5 & & \\
\hline
\end{tabular}

Source: Elaborated by the authors based on data from Harvard Dataverse <https://doi.org/10.7910/DVN/JHD8CV>.

Notes: ${ }^{*}<<0.05, * * p<0.01,{ }^{* * *} \mathrm{p}<0.001$

Model 1 - Unconditional means model

Model 2 - Unconditional growth model

Model 3 - Uncontrolled effects of BFP

Model 4 - Controlled effects of BFP by the "educational past"

Model 5 - Controlled effects of BFP by the "educational past" and quality of local public management

Model 6 - Controlled effects of BFP by the "educational past", quality of local public management and socioeconomic indicators

Models 7 and 8 - Controlled effects of BFP'by the "educational past", quality of local public management, socioeconomic indicators and geographical covariates 
The same strategy adopted to model the evolution of drop-out rates was applied to model progression. The simplest possible linear model was adopted at Level 01 (as a function of time). Other predictors were gradually in

cluded in the models at Level 02. There was a different result here: Model 08 was not better than Model 07 (Table 05). The BIC (which penalises complexity more than AIC does) increased after variables of population size and region were included in the model.

The municipal rate of illiteracy among those aged twenty-five and over, the management capacity of local government (measured by the IGD), per capita income, the Gini coefficient and the proportion of households with an inadequate source of water or sewage discharge were all associated with school progression, with estimates of the expected sign.

As for the variables related to Bolsa Família, coverage was not associated with the initial status of progression, although attendance monitoring was. For a hypothetical municipality presenting the average attendance monitoring (90\%), the predicted initial status of progression would be an impressive 16.4 pp higher than if it had no attendance monitoring at all.

Progression rates increased between 2008 and 2012. The basic rate of change of school progression is $1.7 \mathrm{pp}$ per year. In the models fitted to model progression rates, the covariance between residuals of initial status and of rate of change at Level 01 was negative, which means that higher levels of initial status were associated with smaller rates of change. This can also be interpreted as being compatible with a general tendency for municipalities to converge their progression over the years.

Overall, variables that contribute to a higher initial status of progression are negatively associated with its rate of change, in general with effects of small magnitudes on the rate of change. Our findings reinforce the perception that progression is converging over the years.

\section{Discussion}

In this paper, we sought to understand whether Bolsa Família 01. coverage and 02 . monitoring and enforcement of the educational conditionalities 
were associated with school progression and drop-out rates at the municipal level. To summarise our findings, after controlling for several covariates, the variable proxying cash transfers (Bolsa Família coverage) was not associated with the mentioned educational indicators. The variable proxying conditionalities (school attendance monitoring), however, was negatively associated with drop-out rates and positively associated with school progression.

Based on previous studies, one should expect some effect of transfers on educational indicators and, at best, a limited additional effect of conditionalities. Thus, our findings are somewhat unexpected. However, there are peculiarities to the Brazilian context that might explain our findings. Brazil is a middle-income country with a relatively strong supply of public education. While quality continues to be an issue, only a very small proportion of the school-age population do not have access to public education. Problems that could potentially affect school attendance have been addressed through several different policies. For instance, the National School Meals Programme (Programa Nacional de Alimentação Escolar - Pnae), created in 1955 , reaches the students of public basic education throughout the entire country, while the National School Transportation Programme targets students living in rural areas who face potential difficulties attending school due to long distances from their homes. These policies help to understand why school attendance is high, school progression relatively high, and drop-out rates very low.

In such a context, it is not surprising that our proxy variable for Bolsa Família transfers is at best loosely associated with our educational indicators. However, as this transfer may represent the only stable source of income for the family and is conditional on school attendance, the way conditions are monitored and enforced may have a significant effect on these indicators.

The growth-curve models suggest that the association of attendance monitoring with the initial status of educational indicators was significant and of the expected sign. In other words, higher levels of attendance monitoring were significantly associated with lower levels in the initial status of drop-out and higher levels in the initial status of progression. One could expect that higher attendance monitoring could also be associated with steeper rates of change for both dependent variables (in other words, that higher attendance rates could be associated with 
faster falls in the drop-out rate and a faster increase in the progression rate). However, this is not observed. The growth curve models reveal a tendency for these indicators to converge across Brazilian municipalities. We can conclude that municipalities may have already taken advantage of higher levels of attendance monitoring.

The 'wrong' signs of the main independent variables in their association with rates of change suggest that they should not be considered as an explanation for the convergence of progression and drop-out rates in the Brazilian municipalities; rather, a possible explanation could lie in educational policies ${ }^{16}$. In fact, a whole system of 'weak' accountability was introduced in the Brazilian educational system in the second half of the 2000s. Learning tests (Prova Brasil) were made universal for basic-level students in public schools and the Basic Education Development Index (IDEB - Índice de Desenvolvimento da Educação Básica), an indicator combining progression and proficiency, was adopted in 2007, with specific goals set at school, municipality, state and country levels.

Among other objectives, the system "was designed to bring an end to unproductive grade repetition" (FERNANDES, 2016b, p. 103). Goals were defined aiming at "an expressive reduction in educational inequalities" in school systems (FERNANDES, 2016b, p. 104).

With IDEB, members of the community (both students and parents) are able to evaluate how their school is performing, and teachers, school boards and managers can adopt strategies to improve progression rates and student proficiency. In the short run, it seems intuitive that it would be easier for schools and school systems to increase progression rates rather than improving students' performance in proficiency tests - and there is local evidence to support that this is indeed the case (NARDI, SCHNEIDER and RIOS, 2014). This could contribute to explain the strong convergence in progression rates among municipalities observed in this study, but not why conditionality monitoring is associated with higher progression and lower drop-out rates in the initial status.

This leads us to the main limitations of this paper. First, it is not meant to completely explain the evolution of dropout and progression rates in Brazilian

${ }^{16}$ The authors are very appreciative of an anonymous reviewer for this suggestion. 
municipalities, but only a very small portion of it, emphasising the possible role of transfers and conditionalities. In other words, this is not a work about everything that might possibly influence educational outcomes, but about if and how conditional cash transfers (and their main components) do.

Second, it is an ecological study: it is based on data at the municipality level. As such, it may be subject to ecological fallacy. We found that municipalities with higher levels of school attendance monitoring also have better educational indicators (lower drop-out rates and better school progression). However, the aggregate data used prevents us from being sure that students whose school attendance was monitored by the programme were the ones responsible for better educational indicators. Since the models reported in this paper are subject to ecological fallacy, it is important to understand the possible microfoundations of the association between higher levels of monitoring and the enforcement of conditionalities and better educational indicators. Brollo, Kaufmann, and La Ferrara (2017) looked at how relevant the enforcement of conditionalities is. Their findings suggest that families tend to "fine-tune their behaviour in response to private as well as public signals about the quality of enforcement of the programme" (BROLLO, KAUFMANN, and LA FERRARA, 2017, p. 27). Automatic warning letters and penalties for non-compliance not only have an effect on non-compliant families but also tend to generate spill-over effects "on other families, who learn from the experiences of their children's peers" (BROLLO, KAUFMANN, and LA FERRARA, 2017, p. 27). Therefore, it is reasonable to expect, 'ceteris paribus', better levels of educational indicators in municipalities where attendance monitoring is higher.

The third limitation is that we assumed that the variables 'Bolsa Família coverage' and 'school attendance monitoring' are good proxies for the two dimensions of the Bolsa Família programme (namely, cash transfers and conditionalities). If they are imperfect or entirely inappropriate proxies of these variables, our conclusions might not hold.

\section{Conclusions}

This paper has attempted to add new findings to the ongoing discussion regarding the independent association of cash transfers and conditionalities with 
educational outcomes, using an ecological design. We took advantage of the fact that Bolsa Família coverage (taken as a proxy of cash transfers) and monitoring and enforcement of the educational conditionalities (proxy of conditionalities) are not correlated at the municipal level to fit a number of different OLS and growth-curve models to explain variations in drop-out rates and school progression in basic education in public schools across municipalities.

After controlling for several covariates, we did not find a positive association between Bolsa Família coverage and drop-out and progression rates in either OLS or growth-curve models. On the other hand, monitoring of school attendance was negatively associated with drop-out rates and positively associated with school progression in OLS models. Attendance monitoring was also negatively associated with the initial status of drop-out rates and positively associated with the initial status of progression in the growth-curve models.

The association between attendance monitoring and the rate of change of educational indicators (also in the growth-curve models) was not the same, however, suggesting that its positive effect on educational indicators (found in the initial status) are not strong enough to affect a general tendency for these indicators to converge in the recent Brazilian context.

These results seem to make sense in the Brazilian context, where access to basic education (the first nine school years) is almost universal, a set of policies to support school attendance has been in place for a relatively long time, drop-out rates are at a low level, and progression is relatively high. In this case, it does not come as a surprise that our proxy variable for the modest cash transfers paid by Bolsa Família was not significantly associated with drop-out and progression rates, but that our proxy variable for school attendance monitoring was significantly associated with our educational outcomes

Revised by Eoin Portela Submitted on May 24, 2019 Accepted on May 04, 2020

\section{References}

ADATO, Michelle and HODDINOTT, John (2009), Conditional Cash Transfer Programs: a 'magic bullet' for reducing poverty? In: The poorest and hungry: assessments, analyses and actions. Edited by BRAUN, Joachin von; HILL, Ruth Vargas, and PANDYA-LORCH, Rajul. Washington: International Food Policy Research Institute. pp. 299-306. 
AGATTE, Juliana Picoli (2010), Condicionalidades do Programa Bolsa Família: entre o marco legal e o acompanhamento nos municípios do ABC paulista. Master's dissertation. Instituto de Ciências Humanas. Departamento de Serviço Social. Programa de Pós-Graduação em Política Social. Universidade de Brasilia.

AKRESH, Richard; WALQUE, Damien de, and KAZIANGA, Harounan (2013), Cash transfers and child schooling: evidence from a randomized evaluation of the role of conditionality. Policy Research Working Paper № 6340. Washington: World Bank.

BAEZ, Javier E., and CAMACHO, Adriana (2011), Assessing the long-term effects of conditional cash transfers on human capital: evidence from Colombia. Policy Research Working Paper № 5681. Washington: World Bank.

BAIRD, Sarah; FERREIRA, Francisco H. G.; ÖZLER; Berk, and WOOLCOCK, Michael (2013), Relative effectiveness of conditional and unconditional cash transfers for schooling outcomes in developing countries: a systematic review. Campbell Systematic Reviews. Vol. 09, № 01, pp. 01-124.

BAIRD, Sarah; McINTOSH, Craig, and ÖZLER, Berk (2011), Cash or condition? Evidence from a cash transfer experiment. The Quaterly Journal of Economics. Vol. 126, № 04, pp. 1709-1753.

BARRIENTOS, Armando (2013), Human development income transfers in the longer term. Working Paper № 116 from International Policy Centre for Inclusive Growth.

BICHIR, Renata Mirandola (2011), Mecanismos federais de coordenação de políticas sociais e capacidades institucionais locais: o caso do Programa Bolsa Família. Doctoral thesis. Instituto de Estudos Sociais e Políticos. Programa de PósGraduação em Sociologia e Ciência Política. Universidade do Estado do Rio de Janeiro.

BROLLO, Fernanda; KAUFMANN, Katja, and LA FERRARA, Eliana (2017), Learning about the enforcement of conditional welfare programs: evidence from Brazil. CEPR Discussion Paper № DP11965.

CALDÉS, Natália; COADY, David, and MALUCCIO, John A. (2006), The cost of poverty alleviation transfer programs: a comparative analysis of three programs in Latin America. World Development. Vol. 34, № 05, pp. 818-837.

DE BRAUW, Alan, and HODDINOTT, John (2008), Must conditional Cash Transfer Programs be conditioned to be effective? The impact of conditioning transfers on school enrollment in Mexico. IFPRI Discussion Paper, № 757. Washington: International Food Policy Research Institute.

FERNANDES, Flávio Cireno (2016a), Federalismo, políticas sociais e sistemas de incentivo: o caso do Programa Bolsa Família (2006-2014). Doctoral thesis. 
Faculdade de Filosofia e Ciências Humanas. Departamento de Ciência Política. Programa de Pós-Graduação em Ciência Política. Universidade Federal de Minas Gerais.

FERNANDES, Reynaldo (2016b), A universalização da avaliação e a criação do Ideb: pressupostos e perspectivas. Em Aberto. Vol. 29, № 96, pp. 99-111.

GUANAIS, Frederico C. (2013), The combined effects of the expansion of primary health care and conditional cash transfers on infant mortality in Brazil, 19982010. American Journal of Public Health. Vol. 103, № 11, pp. 2000-2006.

HANLON, Joseph; BARRIENTOS, Armando, and HULME, David (2010), Just give money to the poor: the development revolution from the global South. Sterling: Kumarian Press. 216 pp..

LICIO, Elaine (2012), Para além da recentralização: os caminhos da coordenação federativa do Programa Bolsa Família (2003-2010). Doctoral thesis. Departamento de Serviço Social. Programa de Pós-Graduação em Política Social. Universidade de Brasília.

LINDERT, Kathy; LINDER, Anja; HOBBS, Jason, and BRIERE, Benedict de la (2007), The nuts and bolts of Brazil's Bolsa Família program: implementing conditional cash transfers in a decentralized context. SP Discussion Paper № 709. Washington: World Bank.

LORENZO, Marina Carvalho de (2013), Os desafios para a difusão da experiência do Bolsa Família por meio da cooperação internacional. In: Programa Bolsa Família: uma década de inclusão e cidadania. Edited by CAMPELLO, Tereza and NERI, Marcelo Côrtes. Brasília: Instituto de Pesquisa Econômica Aplicada. pp. 397-415.

NARDI, Elton Luiz; SCHNEIDER, Marilda Pasqual, and RIOS, Monica Piccione Gomes (2014), Qualidade na educação básica: ações e estratégias dinamizadoras. Educação \& Realidade. Vol. 39, № 02, pp. 359-390.

OLIVEIRA, Luis Felipe Batista de and SOARES, Sergei Suarez Dillon (2013), 0 impacto do Programa Bolsa Família sobre a repetência: resultados a partir do Cadastro Único, projeto frequência e censo escolar. Texto para Discussão. Rio de Janeiro: IPEA. 28 pp..

OSTERKAMP, Rigmar (2014), Should income grants in poor countries be conditional or unconditional? Homo Oeconomicus. Vol. 31, № 01/02, pp. 203-224.

PAXSON, Christina and SCHADY, Norbert (2010), Does money matter? The effects of cash transfers on child health and development in rural Ecuador. Economic Development and Cultural Change. Vol. 59, № 01, pp. 187-229. 
PELLERANO, Luca and BARCA Valentina (2014), Does one size fit all? The conditions for conditionality in cash transfers. Working Paper. Oxford Policy Management.

RASELLA, Davide; PEREIRA, Rosana Aquino Guimarães; SANTOS, Carlos Antonio de Souza Teles; SOUSA, Rômulo Paes, and BARRETO, Mauricio Lima (2013), Effect of a conditional cash transfer programme on childhood mortality: a nationwide analysis of Brazilian municipalities. Lancet. Vol. 382, pp. 57-64.

REIMERS, Fernando; SILVA, Carol de Shano da, and TREVINO, Ernesto (2006), Where is the 'education' in conditional cash transfers in education? UNESCO Institute for Statistics Working Paper № 04. Montreal: UNESCO Institute for Statistics.

ROBERTSON, Laura; MUSHATI, Phyllis; EATON, Jeffrey W.; DUMBA, Lovemore; MAVISE, Gideon; MAKONI, Jeremiah; SCHUMACHER, Christina; CREA, Tom; MONASCH, Roeland; SHERR, Lorraine; GARNETT, Geoffrey P.; NYAMUKAPA, Constance, and GREGSON, Simon (2013), Effects of unconditional and conditional cash transfers on child health and development in Zimbabwe: a cluster-randomised trial. Lancet. Vol. 381, № 9874, pp. 1283-1292.

SCHADY, Norbert and ARAUJO, Maria Caridad (2006), Cash transfers, conditions, school enrollment, and child work: evidence from a randomized experiment in Ecuador. World Bank Policy Research Working Paper, № 3930. Washington: World Bank.

SINGER, Judith D. and WILLET, John B. (2003), Applied longitudinal data analysis: modelling change and event occurrence. Oxford: Oxford University Press. 672 pp..

SIMÕES, Armando Amorim and SABATES, Ricardo (2014), The contribution of Bolsa Família to the educational achievement of economically disadvantaged children in Brazil. International Journal of Educational Development. Vol. 39, pp. 151-166.

SOARES, Sergei Suarez Dillon (2012), Bolsa Família, its design, its impacts and possibilities for the future. IPC-IG Working Paper № 89. Brasília: International Policy Centre for Inclusive Growth.

XIMENES, Daniel de Aquino and AGATTE, Juliana Picoli (2011), A gestão das condicionalidades do Programa Bolsa Família: uma experiência intersetorial e federativa. Inclusão Social. Vol. 05, № 01, pp. 11-19.

WORLD BANK (2017), Closing the gap: the state of social safety nets 2017. Paper № 114866. Washington: The World Bank Group.

ZUCCO, Cesar; LUNA, Juan Pablo, and BAYKAL, O. Gokce (2020), Do conditionalities increase support for government transfers? The Journal of Development Studies. Vol. 56, № 03, pp. 527-544. 